\title{
Estimating Added Values of the Integrated Emergency Response System for Airport Accident: Improved Responsiveness and Increased Service Capacity
}

\author{
Ying Guo $\mathbb{D}^{1},{ }^{1}$ Shen Zhang $\mathbb{D}^{1},{ }^{1}$ Zhen Zhang $\mathbb{D},{ }^{2}$ and Qingchun Meng $\mathbb{D}^{1}$ \\ ${ }^{1}$ School of Management, Shandong University, Jinan 250100, China \\ ${ }^{2}$ School of Mathematics, Shandong University, Jinan 250100, China \\ Correspondence should be addressed to Qingchun Meng; meqich@sdu.edu.cn
}

Received 26 July 2017; Accepted 29 March 2018; Published 10 May 2018

Academic Editor: Federica Caselli

Copyright (C) 2018 Ying Guo et al. This is an open access article distributed under the Creative Commons Attribution License, which permits unrestricted use, distribution, and reproduction in any medium, provided the original work is properly cited.

\begin{abstract}
This study presents a framework for estimating the value of response time and quantifying the economic impacts of improved responsiveness and increased service capacity in emergency response systems. In these systems, the value of response time, defined as the number of casualties rescued, forms the basis for understanding the value proposition of the emergency system. Efficiency gains from improved responsiveness are calculated by the difference in the time value function, considering the medical department emergency system as a benchmark. Based on the evaluating systems for welfare gains from price changes, this study will be the first of its kind to adopt the compensating variation method to deal with welfare gains from increased emergency service capacity, while the issue of number of casualties rescued forms the log-linear function of emergency service capacity and supply capacity. Two civil aviation accidents are empirically estimated, illustrating our approaches with specific civil aviation accident cases and examining how other parameters affect improved performance from the responsiveness and welfare arising from service capacity.
\end{abstract}

\section{Introduction}

Our research is motivated by the fact that, in the event of an aviation accident, the likelihood of human injury or even death is high. Furthermore, the ramifications of such an event can have a significant effect on the reputation and economic well-being of a country's air transportation industry [1]. Furthermore, practical data presented in rail accidents and earthquake disasters $[2,3]$ show that, after a disaster occurs, the number of deaths accumulates more quickly at the beginning and then accumulates slowly until reaching the limit. From above high death speed at the beginning of disaster and the huge losses in a disaster, rescuing casualties as soon as possible after the occurrence of natural or man-made disasters, as well as emergency response capacity become critical.

Considering the responsiveness and service capacity as the two key factors in the emergency response system, to design time-efficient and value-efficient emergency logistics for airport and medical emergency department may be desirable, but the process of design is hampered by knowledge, methods, and other types of limited capabilities, especially when the probability of occurrence is extremely low. Thus, given these difficulties and the significance of an aviation emergency, there is a need to make sense of changes in the response time value from when a civil aviation accident occurs and how increased responsiveness and improved service capacity affect emergency response performance because knowing the gains of improved responsiveness and increased service capacity will help in the formulation of time strategies and service resource distributions. This research is driven by this need.

Consequently, our paper will address the following questions: firstly, how the response time value curve after a civil aviation disaster can be described to help emergency managers make sense of the disaster dynamic situations? Secondly, improving the responsiveness can reduce disaster losses based on the death rate function, so many airports build emergency center to conduct the fast-preliminary response, but how does this fast-preliminary strategy improve 
emergency performance? Thirdly, enhancing the service capacity is another method to reduce disaster losses, so how does the service rate of emergency response affect the welfare of the emergency response system?

The researches about emergency management focus on emergency preparation, response, recovery, and such operation actions [4]. Thus, this paper takes the first kind of effort to research the above strategic questions. Firstly, a general function of death rate is proposed based on the death rate curve from real data, and response time value can be calculated by integrating the death rate function from the time of response to the time of stability (i.e., the death rate reduces to zero). Secondly, to estimate the benefit of responsiveness improved by the fast-preliminary strategy, the paper tries to determine the difference in the death rate function before and after introducing the airport's fastpreliminary strategy. In this instance, the service capacity of the fast-preliminary strategy is constant. Finally, as the service capacity is enhanced, on one hand, the death rate may decrease a lot. However, on the other hand, the welfare, which is defined as the soft and hard investment in emergency rescue, may increase a lot. Referring to the methodology developed to estimate the changes in welfare resulting from price changes, we also try to apply Hicks' compensating variation [5] to estimate the welfare gains from improved service capacity made available through a stronger capacity for emergency supplies.

Our research builds on an emergency response system for civil aviation disasters near the airports. In this system, we separate it for two subsystems: one is airport's fastpreliminary response system and one is medical department response system, which are both complementary. Practically, the airport takes a first step to decrease the death rate by putting out a fire, evacuating and classifying the wounded. However, the medical department has the ability to control the death rate, with the problem of relatively slow response speed. Our integrated emergency system, on one hand, reduces the response time uncertainty and, on the other hand, eases the constraint by resources. Consequently, measuring the benefits of responsiveness and welfare of service capacity is regarded as quantifying the gains of constraints of time uncertainty and resource shortage.

Essentially, the resulting estimates of response time value, benefit from increased responsiveness, and welfare gains from improved service capacity will have significant economic and public policy implications, especially as government and emergency managers try to understand and evaluate the value proposition of a comprehensive emergency plan.

The remainder of this paper proceeds as follows. Section 2 reviews the relevant literature pertaining to salvability value change over time and benefits stemming from an improved response time or service rate in the emergency response system. Section 3 presents assumptions abstracted from the real world to simplify research problems and plots the response time value curve. Section 4 develops a method to measure the benefits from increased responsiveness and conducts a sensitivity analysis of key parameters. Then, Section 5 develops a methodology to measure welfare gains from the improved service rate by airport. In Section 6, we apply our results to cases and design numerical cases. Finally, relevant conclusions and implications are drawn in Section 7.

\section{Literature Review}

Dealing with emergency management is a complex process. Extensive researches have been conducted on the management of emergency preparation, response, and recovery [6]. In emergency preparation phase, researches demonstrated that optimal decisions for location and inventory of emergency materials have a direct impact on the responsiveness and capacity of emergency response [7-9]. The distribution and transportation of emergency resources are the main decisions in the process of emergency response $[10,11]$. The emergency recovery is a stage to cope with the debris and rebuild the facilities [12], which attracts less attention compared to preparation and response. In all above three stages, the most complicated and uncertain phase is the emergency response, because of the violation situation and lack of information. So, reviewing the achievements of emergency response, deciding models were proposed with the constraints of arriving time uncertainty and resources shortage, and our paper essentially measures these two constraints. For an emergency response process constrained by resources and uncertain durations, Liu et al. [13] paper presented a method based on an ENet that is a Petri net-based formal model. In addition, both Rawls and Turnquist [14] and Meng et al. [9] also built the stochastic models with the constraints of resources shortage and time uncertainty. Although emergency managers have a growing interest in designing for time-sensitive emergency logistics constrained by resources and uncertain time, there is little research on how to measure the exact value of response time or emergency service capacity, and the issue of how to quantify an emergency response system has been ignored.

To answer the problem of how to measure the exact value of response time or emergency service capacity, literatures related to time value, responsiveness, and service capacity should be referred to in constructing our research. These literatures not only provide us with ideology and methodology, but also help us for our modeling and verifications of the integrated emergency response system.

2.1. Time Value in Emergency Response System. As demonstrated, a faster response in business processes increases competitive advantage, which can be measured by time value [15]. Furthermore, Carmon et al. [16] examined waiting cost from a psychological perspective, illustrating that the accumulated psychological cost is the marginal increasing function of waiting time. These two literatures provided the theoretical basis of response time analysis for business service schemes. As known, emergency response process is more sensitive to time, and Pons et al. [17] verified by hospital real data that a survival benefit was identified when the response time was within 4 minutes for patients with intermediate or high risk of mortality. Berg et al. [18] empirically illustrated how to value patients' time using a contingent valuation method in the health emergency system, where patients' time includes waiting and service times. Chen et al. [19] proposed an assessment 
concept model for emergency response phase by analyzing the influencing factors of during-incident process assessment and provided mitigability, rescuability, and recoverability as three dimensions to quantitatively characterize the evolution of incidents and corresponding responses. Earlier works motivate our models, and a significant difference between one of our models and previous research on emergency response systems is the saving value from the responsive actions we explicitly capture, which we refer to as response time value.

2.2. Responsiveness in Emergency System. Response time represents responsiveness and improving responsiveness is significant. For example, an empirical estimating study demonstrated 13 deaths per year because of the delayed response in one Australian emergency department [20]. As such, numerous researchers contributed to the development of a design strategy to improve the responsiveness of the emergency system. Furthermore, most published models for emergency service management are proposed to improve responsiveness based on management science, and many are applied to implement new policies and practices, particularly in policing and firefighting [21]. Both Saghafian et al. [22] and Song et al. [23] came up with queuing strategies in emergency department to improve responsiveness; they measured the performance of strategies by the reduced waiting time with or without increasing costs. However, all above literatures just studied the means to increase the responsiveness in emergency department; with further effort, some literatures calculated the operational costs of the means. Motivated by several strategies to improve responsiveness, we attempt to evaluate the benefits arising from improved responsiveness, which can help analyze the separated or synthesized efficiency of different strategies.

2.3. Service Capacity in Emergency System. Investing in emergency service capacity can reduce response time more than nonresponsive action and decrease costs more than prepositioning [24]. In addition to this advantage, the results of Akşin et al. [25] showed that the probability of abandoning service would increase as the service quality degrades for high priority callers. Thus, emergency managers have become increasingly interested in investing in emergency service capacity. Nohrstedt [26] and Yi et al. [27] positively related service capacity to service delivery and effectiveness of treatment for emergency rescue in emergency management systems. Designing a dynamic resource distribution mechanism can reduce the probability of excessive response times and substantially smooth the workload of emergency crews [28]. In terms of evaluation, few works have researched the methods to quantify the performance of service capacity. Novak and Sullivan [29] evaluated accessibility to emergency services through a road network referred to as critical closeness accessibility. To fill the research gap from the theoretical and empirical perspectives, we represent a first effort by applying the consumer surplus methodology to measure welfare from increased service capacity. In this regard, Hausman [30] developed a closed-form solution to measure compensating variation under standard linear or log-linear demand functions.

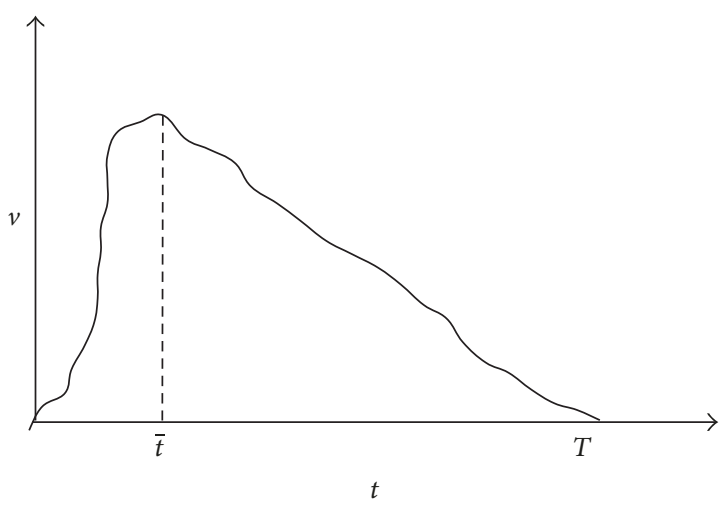

FIGURE 1: Death rate curve after the occurrence of an accident.

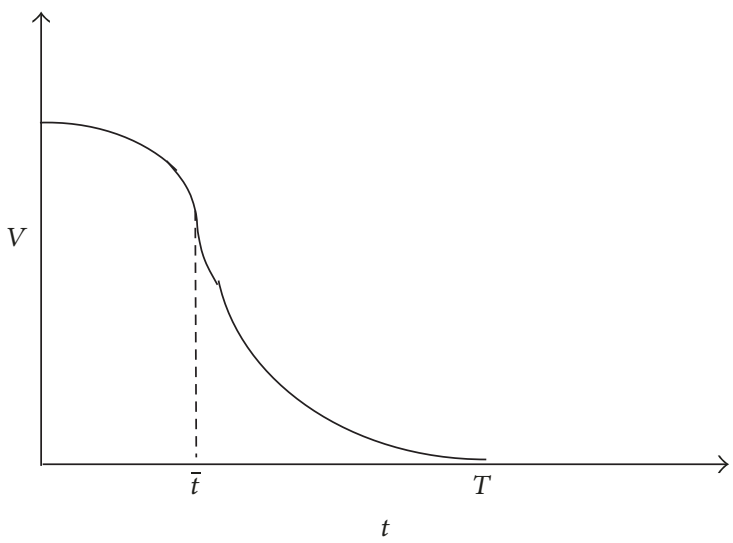

FIGURE 2: Time value curve after the occurrence of a civil aviation disaster.

The review shows that little empirical effort has focused on examining the effect of response time in terms of response time value, the effect of improved responsiveness, and the effect of increased service capacity. In order to effectively deal with the difficulties in fuzzy knowledge for emergency response systems, our study takes a business perspective on how to make emergency response beneficial, builds on existing studies by introducing a benefit measurement that utilizes economic and compensating variation approaches, and verifies the constraints of emergency resources shortage and time uncertainty.

\section{Assumption and Time Value Curve}

3.1. Assumption and Relevant Notation. In this paper, we assume that (1) the death rate after a disaster is a nonmonotonous function of the passing time. This assumption can be explained by Figure 1 and Figure 2 in the introduction. (2) The measured time value can be understood as how much effort the response action needs to prevent casualties from dying, represented by the number of rescued lives. However, the economic and social value of a person may differ between casualties, making it difficult to measure the response time value. From another perspective, the value of life is not easily measured; thus, we regard the value of life as 
equal, which is supported by the compensation mechanism in China and worldwide. (3) All fast-preliminary responses by airports have limited capacity. Therefore, the main function of airports' fast response is to control and decrease the death rate, not to stop death, which needs a more powerful capacity. This assumption is reasonable, because of the serious consequences associated with civil aviation accidents and the limited emergency supplies providing relief to those in need. (4) The responses of medical departments have stronger ability; therefore, we assume that their response can completely stop people from dying. The stronger service abilities of medical departments overestimate the relieved casualties; thus, this assumption would underestimate true gains derived from increased responsiveness. (5) The response time of airports' fast-preliminary responses satisfies $0 \leq t_{a} \leq \bar{t}$, and the response time of medical departments satisfies $\bar{t} \leq t_{h} \leq T$, where $t_{a}$ and $t_{h}$ represent the response time of airports, $\bar{t}$ means the critical time during a disaster, and $T$ denotes the natural ending time for a disaster without taking action.

For the purpose of our analysis, the following notations are used:

$t$ : waiting time after the occurrence of a civil aviation accident;

$\bar{t}$ : critical time during the disaster responsive phase;

$T$ : natural ending time for a disaster without taking action;

$t_{a}$ : response time of airports in the integrated emergency response system;

$t_{h}$ : response time of medical departments in the medical department response system;

$t_{d}$ : response time of medical departments in the integrated emergency response system;

$v(t)$ : the death rate, a nonmonotonous function of waiting time;

$V(t)$ : the responsive time value function;

$u$ : service rate of airports' fast-preliminary response;

$A, B$ : two positive constant variables in the death rate function;

$\alpha$ : the time elastic parameter of death rate when the death rate increases;

$\beta$ : the time elastic parameter of death rate when the death rate decreases.

3.2. Model and Time Value Curve. Referring to the practical data on deaths in the Wenchuan earthquake, road crashes, and railway accidents, the death rate curve can be described similarly in Figure 1 with time passing [28, 31, 32]. Thus, we assume the death rate function as follows. Generally, the piecewise function is adopted to describe types of nonmonotonous functions [33] when the dependent variable first increases and then decreases with the independent variable.

$$
v(t)= \begin{cases}A t^{\alpha} & 0 \leq t \leq \bar{t} \\ -B(t-\bar{t})^{\beta}+A \bar{t}^{\alpha} & \bar{t} \leq t \leq T\end{cases}
$$

As shown in Figure 1, the death rate function is continuous, and this assumption is available, which leads to the following relationship:

$$
B=\frac{A \bar{t}^{\alpha}}{(T-\bar{t})^{\beta}} .
$$

Using the integral theory, we calculate the time value function for responsiveness when the responsive time value is measured by the total number of people who will avoid death.

For every possible response time $t, \forall t \in[0, \bar{t}]$, then

$$
\begin{aligned}
V_{1}(t) & =\int_{t}^{\bar{t}} A x^{\alpha} d x+\int_{\bar{t}}^{T}\left(-B(x-\bar{t})^{\beta}+A \bar{t}^{\alpha}\right) d x, \\
\frac{d V_{1}(t)}{d t} & =-A t^{\alpha} \leq 0, \\
\frac{d^{2} V_{1}(t)}{d t^{2}} & =-A \alpha t^{(\alpha-1)} \leq 0 .
\end{aligned}
$$

$\forall t \in[\bar{t}, T]$, we have

$$
\begin{aligned}
V_{2}(t) & =\int_{t}^{T}\left(-B(x-\bar{t})^{\beta}+A \bar{t}^{\alpha}\right) d x, \\
\frac{d V_{2}(t)}{d t} & =A \bar{t}^{\alpha}\left(\left(\frac{t-\bar{t}}{T-\bar{t}}\right)^{\beta}-1\right) \leq 0, \\
\frac{d^{2} V_{1}(t)}{d t^{2}} & =A \bar{t}^{\alpha} \beta\left(\frac{t-\bar{t}}{T-\bar{t}}\right)^{\beta-1} \frac{1}{T-\bar{t}} \geq 0 .
\end{aligned}
$$

In the whole,

$$
V(t)= \begin{cases}V_{1}(t) & 0 \leq t \leq \bar{t} \\ V_{2}(t) & \bar{t} \leq t \leq T .\end{cases}
$$

From above response time value function, we can find that (1) the response time value function is continuous in time window $[0, T]$; (2) the function is a monotonically decreasing function of response time; (3) the decreasing speed reaches the maximum when $t=\bar{t}$; (4) the function is a concave function in $[0, \bar{t}]$ and then becomes a convex function during $[\bar{t}, T]$.

A complete analysis of the characteristics of the response time value function describes the time value curve for responses, as presented in Figure 2. From the perspective of the time value curve, two intuitive and quick comprehensions are highlighted. One is that, after a civil aviation disaster, the sooner the responsive actions are taken, the higher the time value is. The other is that when the starting time of rescue activities is later than the critical waiting time $\bar{t}$, the time value decreases rapidly. These comprehensions are in accordance with the general changing law in an emergency situation. We call the response time $\bar{t}$ the critical time, similar to regarding 72 hours as the critical time during earthquake disasters.

The analysis of the nonhomogeneous time value explains the dynamic mechanism of a civil aviation disaster and can aid decision-making in terms of uncertainty and violation. In 
addition, clarifying the time value enables an evaluation of the severity and more accurately predicts losses, which improves the economic and reasonable distribution of emergency sources. For example, the volume of emergency resources to be distributed can be evaluated when rescue organizations initiate responsive actions by using the time value curve, which will decrease additional operational costs and opportunity risk losses. Using a numerical example, if the time value is 50 at time 10 , then rescue units should distribute 50 units of emergency materials (e.g., blood bags, defibrillators) when rescue units arrive at time 10. Distributing 40 units of emergency materials will result in 10 units of opportunity losses, and 55 units will result in a waste of 5 units, because the emergency materials are perishable and fragile. This further demonstrates the importance of a response time before critical $\bar{t}$.

In this paper, the evaluation of time value depends on the total losses when rescue units cannot arrive in time and opportunity losses. Generally, with societal and economic development, the air industry has thrived and prospered, now needing a stronger responsive ability to avoid losses. Therefore, ways to increase time value should shift from how to save response time to how to decrease the death rate after a civil aviation disaster. In this regard, the common and popular means are improving responsiveness by the fast-preliminary strategy and enhancing service capacity by the sufficient soft and hard investment. One strategy of the fast-preliminary response for airports is to take fast and preliminary actions using stored emergency materials prepared in advance, which has a cost of insufficient service capacity; that is to say, this fast-preliminary response will not have enough capacity to control the death rate. The strategy of enhancing service capacity is following naturally, but the service capacity is constrained by limited emergency resources within a short time window. Thus, modeling and verifying the responsiveness and service capacity will help emergency managers design time-efficient and value-efficient response system.

\section{Benefits from Increased Responsiveness by Fast-Preliminary Response}

The preceding analysis demonstrates the social benefits of decreasing delays for emergency response. To derive the benefits of a fast-preliminary strategy, we analyze two emergency response systems, namely, a medical department emergency response system (MDERS) where no airport takes responsive action after a disaster and an integrated emergency response system (IERS) where an airport initiates a fast-preliminary response and medical departments take responsive actions later. Viewing the medical department emergency system as a benchmark, then we can obtain the benefits of improved responsiveness by letting the saved people in the integrated emergency response system minus that in Medical Department System. In practice, this minus can be done between two similar civil aviation accidents in different time or different place, one accident rescue with the fast-preliminary response and the other one without.

Combining assumptions (3) and (4) in Section 3.1 with the analysis above, the death rate curve changes after taking

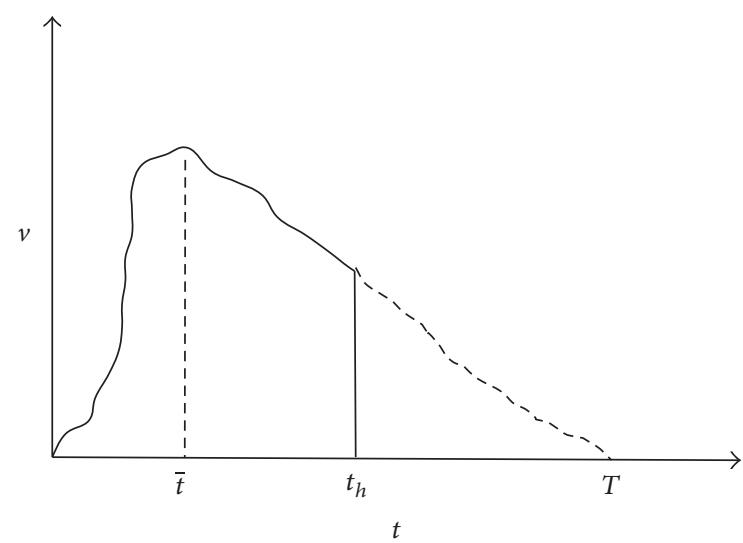

(a) Medical department emergency response system

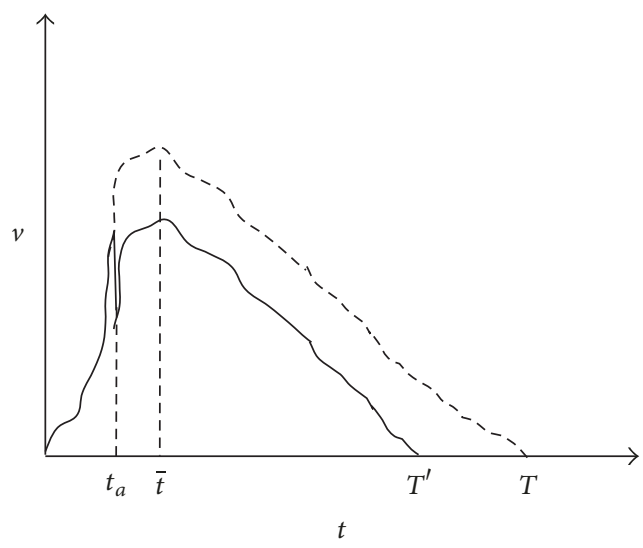

(b) Integrated emergency response system

FIgURE 3: Death rate curve after taking action.

action, as shown in Figure 3. In Figure 3, the solid lines represent the real death rate trend after taking responsive action, while the dotted lines represent the initial death rate trend if no responsive action is adopted. From the piecewise function, two scenarios $\left(t_{d} \geq T^{\prime}\right.$ and $\left.t_{d} \leq T^{\prime}\right)$ are discussed. Here, we assume that the service capacity is invariant, and this is reasonable because the fast-preliminary strategy just works before the medical departments' arrival within a short time window.

4.1. Benefits of Integrated Emergency Response Systems Where $t_{d} \geq T^{\prime}$. Based on the assumptions that $0 \leq t_{a} \leq \bar{t}$ and $\bar{t} \leq t_{h} \leq T$, with $u$ denoting the constant service rate of an airport's fast-preliminary response, the death rate function is as follows:

$$
v^{c}(t)= \begin{cases}A t^{\alpha} & 0 \leq t \leq t_{a}, \\ A t^{\alpha}-u & t_{a} \leq t \leq \bar{t}, \\ -B(t-\bar{t})^{\beta}+A \bar{t}^{\alpha}-u & \bar{t} \leq t \leq T .\end{cases}
$$

Using the integral expressions for expected opportunity losses, the expected benefits $E_{h}$ when medical departments 
take actions in time without a fast-preliminary response are computed as follows:

$$
\begin{aligned}
E_{h}= & \int_{t_{h}}^{T}\left(-B(t-\bar{t})^{\beta}+A \bar{t}^{\alpha}\right) d t \\
= & -B \frac{1}{\beta+1}(T-\bar{t})^{\beta+1}+A \bar{t}^{\alpha} T+B \frac{1}{\beta+1}\left(t_{h}-\bar{t}\right)^{\beta+1} \\
& -A \bar{t}^{\alpha} t_{h} .
\end{aligned}
$$

Similarly, the expected benefits $E_{1}$ when airports initiate fast-preliminary responses with a constant service rate are calculated as follows:

$$
\begin{aligned}
E_{1} & =\int_{t_{a}}^{\bar{t}} A \bar{t}^{\alpha} d t+\int_{\bar{t}}^{T}\left(-B(t-\bar{t})^{\beta}+A \bar{t}^{\alpha}\right) d t \\
& -\left[\int_{t_{a}}^{\bar{t}}\left(A \bar{t}^{\alpha}-u\right) d t\right. \\
& \left.+\int_{\bar{t}}^{T^{\prime}}\left(-B(t-\bar{t})^{\beta}+A \bar{t}^{\alpha}-u\right) d t\right]=-B \frac{1}{\beta+1}(T \\
& -\bar{t})^{\beta+1}+A \bar{t}^{\alpha} T+B \frac{1}{\beta+1}\left(T^{\prime}-\bar{t}\right)^{\beta+1}-A \bar{t}^{\alpha} T^{\prime} \\
& +u\left(T^{\prime}-t_{a}\right),
\end{aligned}
$$

where $T^{\prime}$ satisfies $-B\left(T^{\prime}-\bar{t}\right)^{\beta}+A \bar{t}^{\alpha}-u=0$ and $T^{\prime} \leq T$.

Airports initiate a fast-preliminary response if it is more beneficial to rescue casualties; otherwise, this response should be discarded, which causes great additional operational costs. The following relationship should be constructed ((8) minus (7)):

$$
\begin{aligned}
\pi^{1}= & B \frac{1}{\beta+1}\left[\left(T^{\prime}-\bar{t}\right)^{\beta+1}-\left(t_{h}-\bar{t}\right)^{\beta+1}\right] \\
& -A \bar{t}^{\alpha}\left(T^{\prime}-t_{h}\right)+u\left(T^{\prime}-t_{a}\right) \geq 0 .
\end{aligned}
$$

Because $B=A\left(\bar{t}^{\alpha} /(T-\bar{t})^{\beta}\right)$ and

$$
\begin{aligned}
& \left(T^{\prime}-\bar{t}\right)^{\beta+1}-\left(t_{h}-\bar{t}\right)^{\beta+1}=\left(T^{\prime}-t_{h}\right)\left[\left(T^{\prime}-\bar{t}\right)^{\beta}\right. \\
& \quad+\left(T^{\prime}-\bar{t}\right)^{\beta-1}\left(t_{h}-\bar{t}\right)+\cdots+\left(T^{\prime}-\bar{t}\right)\left(t_{h}-\bar{t}\right)^{\beta-1} \\
& \left.\quad+\left(t_{h}-\bar{t}\right)^{\beta}\right],
\end{aligned}
$$

then

$$
\begin{aligned}
& u\left(T^{\prime}-t_{a}\right) \geq A \bar{t}^{\alpha}\left(T^{\prime}-t_{h}\right) \\
& \cdot\left[1-\frac{1}{\beta+1}\left(\sum_{n=0}^{\beta} \frac{\left(T^{\prime}-\bar{t}\right)^{\beta-n}\left(t_{h}-\bar{t}\right)^{n}}{(T-\bar{t})^{\beta}}\right)\right] .
\end{aligned}
$$

From the above condition, we can conclude that (1) if $T^{\prime} \leq t_{h}$, then $u \geq A \bar{t}^{\alpha}\left[1-\left(t_{h}-\bar{t}\right)^{\beta} /(T-\bar{t})^{\beta}\right]$; in this instance $\forall t_{a} \in\left[0, T^{\prime}\right]$, a fast-preliminary response is good. (2) If $T^{\prime}>t_{h}$, a fast-preliminary response is good when $t_{a} \leq t_{a}^{1, M}$ is asked.

Denoting by $t_{a}^{1, M}$ the latest response time in an airport's fast-preliminary strategy, we calculated

$$
\begin{aligned}
& t_{a}^{1, M} \\
& =\frac{(\beta+1) t_{h}(T-\bar{t})^{\beta}-\left(\beta T^{\prime}+\bar{t}\right)\left(T^{\prime}-\bar{t}\right)^{\beta}-\left(t_{h}-\bar{t}\right)^{\beta+1}}{(\beta+1)\left[(T-\bar{t})^{\beta}-\left(T^{\prime}-\bar{t}\right)^{\beta}\right]} .
\end{aligned}
$$

(1) First, $\partial t_{a}^{1, M} / \partial t_{h} \geq 0$. This expression illustrates the responsiveness of a fast-preliminary response allied with the responsiveness of the emergency system. If the original responsiveness of a medical department is slow, a fastpreliminary response has a relaxed standard. Thus, improving the responsiveness of medical departments may obviously improve the performance of responsive work. Second, we have $\partial t_{a}^{1, M} / \partial T \geq 0$. For a disaster with a certain severity measured by death rate and duration time, a longer duration of the disaster means a slower death rate, reducing the sensitivity of the time factor. Therefore, speed can be reduced when the degree of injury is relatively low to improve the quality of a fast-preliminary response through complete information and full preparation. Last, $\partial t_{a}^{1, M} / \partial T^{\prime} \leq 0$. If the airport wants to decrease the death rate to zero earlier through a fast-preliminary response, stronger emergency capacity is needed. Essentially, a more efficient service capacity is required, which decreases the requirement of response time, leading to a looser latest response time. Thus, in order to design the fast-preliminary strategy, the latest response time of airport should be considered one key indicator, as well as the improved performance.

(2) $\partial \pi^{1} / \partial t_{h}=A \bar{t}^{\alpha}\left[1-\left(t_{h}-\bar{t}\right)^{\beta} /(T-\bar{t})^{\beta}\right]$, which is nonnegative since $t_{h} \leq T$. We note that every unit increase of a medical department's responsiveness, that is, a shorter medical department response time, decreases the improved performance of a fast-preliminary response by $A \bar{t}^{\alpha}\left[1-\left(t_{h}-\right.\right.$ $\left.\bar{t})^{\beta} /(T-\bar{t})^{\beta}\right]$ units. In addition, the decrements increase when the medical department's responsiveness increases, which illustrates that responsiveness plays a significant role in improving the level of emergency management. The above analysis demonstrates that a fast-preliminary strategy can be discarded if the medical department has sufficient responsive ability.

(3) $\partial \pi^{1} / \partial T=-\left(A \bar{t}^{\alpha} \beta\left(\left(T^{\prime}-\bar{t}\right)^{\beta+1}-\left(t_{h}-\bar{t}\right)^{\beta+1}\right)\right) /((\beta+$ 1) $\left.(T-\bar{t})^{\beta+1}\right) \leq 0$ because of $t_{h} \leq T^{\prime} \leq T$. Obviously, the efficiency of a fast-preliminary response decreases when the disaster duration increases, while the decrement decreases. This expression provides the theoretical basis that a fastpreliminary strategy may be wasteful when the duration of a civil aviation disaster is long enough; in other words, the severity of the disaster is serious enough. This conclusion must be verified by actual data, because not enough information is available to support it. 
(4) $\partial \pi^{1} / \partial T^{\prime}=-A \bar{t}^{\alpha}\left(\left(\beta\left(T^{\prime}-t_{a}\right)\left(T^{\prime}-\bar{t}\right)^{\beta-1}\right) /(T-\bar{t})^{\beta}\right)$, which is nonpositive. Understandably, improved performance is confined, because of the long service duration consequent to a low service rate. However, the effect of service capacity on improved performance decreases when service duration increases. In other words, the few service rate increments from a low service rate have no significant contribution, while the few service rate increments from a high service rate may have a great contribution. Thus, a fastpreliminary response should not be initiated when the airport is not fully prepared.

(5) Compared to the situation where the service capacity is exponentially decaying with $u_{0} e^{-\delta\left(t-t_{a}\right)}$, we find that a fastpreliminary strategy may be wasteful when the severity of the disaster is serious enough. For the effects of the duration of the disaster, we have $\partial \pi^{v} / \partial T=-\left(A \bar{t}^{\alpha} \beta\left(\left(T^{\prime \prime}-\bar{t}\right)^{\beta+1}-\left(t_{h}-\right.\right.\right.$ $\left.\left.\bar{t})^{\beta+1}\right)\right) /\left((\beta+1)(T-\bar{t})^{\beta+1}\right)$ and $\left|\partial \pi^{v} / \partial T\right| \leq\left|\partial \pi^{1} / \partial T\right|$, and the improved performance by a decaying service capacity is less sensitive to disaster severity. As we all know, a sufficient emergency preparation in airport can hold the service capacity constant; therefore, if the disaster is serious, with a decaying service capacity (insufficient emergency preparation in fastpreliminary response), even not implementing a fast response is appreciated, which is counterintuitive.

4.2. Benefits of Integrated Emergency Response Systems Where $t_{d} \leq T^{\prime}$. The integrated emergency response system is now formulated for airports' fast-preliminary response and the response of medical departments. In this instance, the medical department's response can be allowed to delay collecting complete information for emergency distribution decisions based on the premise of implementing a fast-preliminary response, meaning $t_{d} \geq t_{h}$. Thus, we study here the effect of the delay on the latest response time and efficiency of a fastpreliminary response. To provide closed-form expressions, we model the delay in a specific situation where the service rate of an airport's fast response is a constant value.

Similarly, based on the death rate for integrated emergency system in Figure 4, the expected benefits $E_{h}$ when medical departments take action in time with no fastpreliminary response are computed as in (7).

While the expected benefits of the integrated emergency system $E_{i}$ will be expressed as (13), here, we assume $t_{d} \leq T^{\prime}$, which is the same when no medical department response is implemented.

$$
\begin{aligned}
E_{2} & =\int_{t_{a}}^{\bar{t}} A \bar{t}^{\alpha} d t+\int_{\bar{t}}^{T}\left(-B(t-\bar{t})^{\beta}+A \bar{t}^{\alpha}\right) d t \\
& -\left[\int_{t_{a}}^{\bar{t}}\left(A \bar{t}^{\alpha}-u\right) d t\right. \\
& \left.+\int_{\bar{t}}^{t_{d}}\left(-B(t-\bar{t})^{\beta}+A \bar{t}^{\alpha}-u\right) d t\right]=-B \frac{1}{\beta+1}(T \\
& -\bar{t})^{\beta+1}+A \bar{t}^{\alpha} T+B \frac{1}{\beta+1}\left(t_{d}-\bar{t}\right)^{\beta+1}-A \bar{t}^{\alpha} t_{d} \\
& +u\left(t_{d}-t_{a}\right) .
\end{aligned}
$$

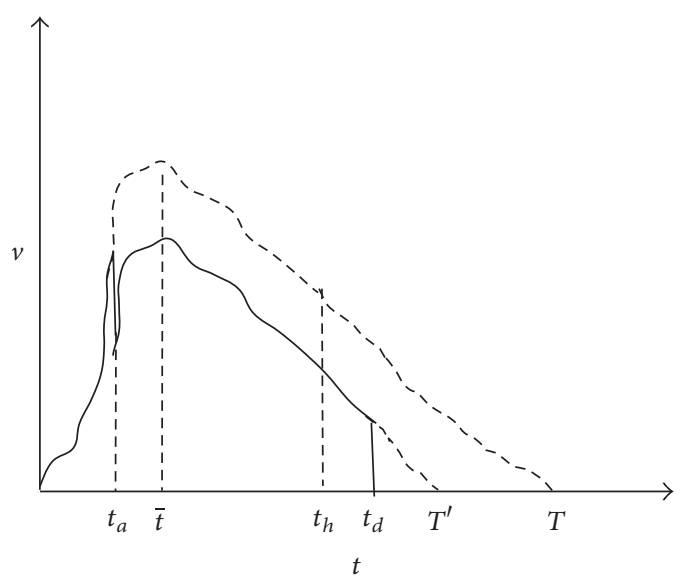

FIGURE 4: Death rate for the integrated emergency response system.

By using (13) and subtracting (8), we obtain the improved performance by the integrated emergency system compared to only the medical department response, as shown in (14).

$$
\begin{aligned}
\pi^{2}= & B \frac{1}{\beta+1}\left[\left(t_{d}-\bar{t}\right)^{\beta+1}-\left(t_{h}-\bar{t}\right)^{\beta+1}\right] \\
& -A \bar{t}^{\alpha}\left(t_{d}-t_{h}\right)+u\left(t_{d}-t_{a}\right) .
\end{aligned}
$$

Based on this expression and the analysis above, the following conclusions are deduced.

(1) When the medical department response time is late in the integrated emergency system, small improvements in the medical department's responsiveness will greatly relax an airport's fast responsiveness, since $t_{a}^{2, M}=t_{d}-\left(A \bar{t}^{\alpha} / u\right)\left(t_{d}-\right.$ $\left.t_{h}\right)+(B / u)(1 /(\beta+1))\left(\left(t_{d}-\bar{t}\right)^{\beta+1}-\left(t_{h}-\bar{t}\right)^{\beta+1}\right)$, where the firstorder derivative $t_{d}$ is nonpositive because of $t_{d} \leq T^{\prime}$. When $t_{d}=T^{\prime}$, the latest response time is at its smallest value. The decremented units by every incremental unit of delay time $t_{d}$ is $1-\left(A \bar{t}^{\alpha} / u\right)\left(1-\left(t_{d}-\bar{t}\right)^{\beta} /(T-\bar{t})^{\beta}\right)$, which increases with the increase of delay time $t_{d}$.

(2) When the medical department response time is late in the integrated emergency system, small improvements in a medical department's responsiveness will greatly improve performance for the integrated emergency system, as computed by the first-order derivative expression, $\partial \pi^{2} / \partial t_{d}=$ $-A \bar{t}^{\alpha}\left(\left(\left(T^{\prime}-\bar{t}\right)^{\beta}-\left(t_{d}-\bar{t}\right)^{\beta}\right) /(T-\bar{t})^{\beta}\right)$, which is nonpositive. In addition, the second-order derivative $\partial^{2} \pi^{2} / \partial t_{d}^{2}=$ $A \bar{t}^{\alpha}\left(\left(\beta\left(t_{d}-\bar{t}\right)^{\beta-1}\right) /(T-\bar{t})^{\beta}\right) \geq 0$ indicates that the sensitivity of delay time $t_{d}$ increases with the length of waiting time for being dealt with by medical departments.

(3) High medical department responsiveness brings stresses for improving responsive performance by adopting a fast-preliminary strategy. As such, $\partial \pi^{2} / \partial t_{h}=A \bar{t}^{\alpha}\left(1-\left(t_{h}-\right.\right.$ $\left.\bar{t})^{\beta} /(T-\bar{t})^{\beta}\right)=\partial \pi^{1} / \partial t_{h}$ indicates that the initial response time in the medical department emergency system has the same effects on improved performance through a fast-preliminary strategy in the only airport response emergency system as that in the integrated emergency system. 
(4) A fast-preliminary strategy should be discarded when the severity of the disaster is high, since $\partial \pi^{2} / \partial T=$ $-\left(A \bar{t}^{\alpha} \beta\left(\left(t_{d}-\bar{t}\right)^{\beta+1}-\left(t_{h}-\bar{t}\right)^{\beta+1}\right)\right) /\left((\beta+1)(T-\bar{t})^{\beta+1}\right) \leq 0$ and $\left|\partial \pi^{2} / \partial T\right| \leq\left|\partial \pi^{1} / \partial T\right|$. Note that the duration of the disaster negatively affects improved performance, which can also be explained as follows. If the disaster seems very serious, a fastpreliminary strategy is not that beneficial, and the effect of reduction on the only airport response emergency system is more obvious.

(5) A fast-preliminary response is more efficient and beneficial if the airport has a high service capacity. In addition, improved performance by increasing the service rate in the only airport response emergency system is greater than that in the integrated emergency system. This conclusion is demonstrated by $\partial \pi^{2} / \partial T^{\prime}=-\left(A \bar{t}^{\alpha} \beta\left(t_{d}-t_{a}\right)\left(T^{\prime}-\bar{t}\right)^{\beta-1}\right) /(T-$ $\bar{t})^{\beta} \leq 0$ and $\left|\partial \pi^{2} / \partial T^{\prime}\right| \leq\left|\partial \pi^{1} / \partial T^{\prime}\right|$. Thus, the medical department response strategy should be discarded if the airport has a high service capacity, which can greatly decrease the responsive costs of medical departments and emergency systems.

\section{Welfare Gains from Increased Service Capacity}

This content applies and extends existing welfare estimation techniques to measure the welfare gains from an increased service capacity made available through an increased service rate. In our paper, welfare means the reduced emergency supplies. Therefore, although the enhanced service capacity saved more people, we do not evaluate it. And the only welfare gains underestimate the whole benefits of increased service capacity by investment. To do this, we define the total effect of increased service capacity on welfare as the difference in the emergency expenditure function before and after improving service capacity, as measured by the compensating variation [34]. We define the service capacity as the saved rate, that is, how much people is saved every minute, which means larger is better. Here, let $\tau=1 / \mathcal{u}$; a smaller $\tau$ is better.

$$
\mathrm{CV}=e\left(\tau_{0}, \theta_{1}\right)-e\left(\tau_{1}, \theta_{1}\right)
$$

where $\tau_{0}$ and $\tau_{1}$ are the parameters of service time of pre- and post-improved response service capacity, respectively, and $\theta_{1}$ is the post-improved level of responsiveness utility. In effect, (15) measures the length of emergency service time, which must be compensated to be as well as after improving service capacity.

To apply (15) in practice, we specify a standard log-linear rescue function for casualties (i.e., number of casualties rescued) in a civil aviation disaster by the emergency response, as shown in (16), since the log-linear function fits various data well [34].

$$
r(\tau, s)=H \tau^{\gamma} s^{\varepsilon}
$$

where $\tau$ is the service time for one casualty when a fast emergency response is taken after a disaster, $s$ is the limited emergency supplies capacity (the gross working time of rescue or the ending time of the response), $\gamma$ is the elasticity of service time, and $\varepsilon$ is the elasticity of supplies capacity. Following the literature [30], we adopted Roy's identity to rewrite (16) as a function of the indirect utility function:

$$
r(\tau, s)=-\frac{\partial \Phi(\tau, s) / \partial \tau}{\partial \Phi(\tau, s) / \partial s}
$$

where $\Phi(\tau, s)$ is the indirect utility function, a decreasing function of $\tau$, and increasing function of $s$. Solving this partial differential equation gives

$$
\Phi(\tau, s)=-H \frac{\tau^{1+\gamma}}{1+\gamma}+\frac{s^{1-\varepsilon}}{1-\varepsilon}
$$

and the emergency expenditure function:

$$
e(\tau, \theta)=\left[(1-\varepsilon)\left(\theta+\frac{H \tau^{1+\gamma}}{1+\gamma}\right)\right]^{1 /(1-\varepsilon)} .
$$

Combining (15) and (19), the welfare gain from increased responsiveness can be provided by

$$
\mathrm{CV}=\left[\frac{1-\varepsilon}{1+\gamma} s^{-\varepsilon}\left(\tau_{0} r_{0}-\tau_{1} r_{1}\right)+s^{1-\varepsilon}\right]^{1 /(1-\varepsilon)}-s
$$

where $\mathrm{CV}$ is the compensating variation, $\varepsilon$ is the emergency supplies elasticity estimate, $\gamma$ is the unit service time elasticity, $s$ is the emergency supplies capacity, $\left(\tau_{1}, r_{1}\right)$ are the unit service time and rescue quantity after improving service capacity, and $\left(\tau_{0}, r_{0}\right)$ are the unit service time and rescue quantity before improving service capacity.

As the working time of the emergency response can be extended until the disaster is under control, the effects of the elasticity of emergency supplies capacity can be ignored for typical emergency responses where working time would be sufficient. Applying this assumption, that is, $\delta=0$, the equation of CV simplifies to

$$
\mathrm{CV}=\frac{\tau_{0} r_{0}-\tau_{1} r_{1}}{1+\gamma}
$$

\section{Computational Results}

As part of our analysis, we use numerical methodologies to provide further insight into the analytical results in Sections 4 and 5. The data used in these experiments are inspired by the aviation accident reports of the National Transportation Safety Board (NTSB), safety reports of the International Civil Aviation Organization (ICAO), and accident reports of the State Administration of Work Safety. To provide a comprehensive computational analysis, two accident reports are adopted. One is for the Asiana Airlines Flight 214, Boeing 777-200ER, HL7742, in San Francisco, California on July 6, 2013. The other is for United Airlines Flight 232, McDonnell Douglas DC-1040, at Sioux Gateway Airport, Sioux City, Iowa on July 19, 1989, which is used as a benchmark for the 
TABLE 1: Specific values of parameters.

\begin{tabular}{cccc}
\hline$t_{a}$ & $\bar{t}$ & $t_{d}$ & $u$ \\
\hline $5 \min$ & $19 \min$ & $92 \mathrm{~min}$ & 0.35 persons $/ \mathrm{min}$
\end{tabular}

comparison. Both the two disasters crashed on runway, and the passenger are about 300 people. The differences between them include two aspects. One is that the responsiveness and service capacity are weakly prepared for and underequipped in the 1989 disaster, which is based on accident reports from the 1960s to the 1980s, and the other one is higher degree of disaster severity in the 1989 accident. No matter the weaker response system or the more serious degree will result in higher death rate. In regard of this, we select an enough small discount factor valued as 0.1 to relax the element of severity; this little value may underestimate the benefits of responsiveness and service capacity, so our outcomes are conservative.

6.1. Estimated Values of Parameters and Models. The emergency response to this accident can be distinguished as two phases, namely, the airport's fast-preliminary response (e.g., firefighting, extricating passengers, and rapid assessment of patients' condition) and the medical department's response. Although the original data collected are for the airport emergency response before 13:00, 92 minutes from the time of occurrence, the benefits of improved responsiveness made available through a fast-preliminary strategy can be evaluated. This situation can be viewed as a specific case where $t_{d} \geq T^{\prime}$. Furthermore, improved medical department responsiveness in the integrated emergency response time can also be estimated, which is helpful in designing time strategies for airports and medical departments in the integrated emergency response system. The response times and service times of the airport emergency response system are presented in Table 1.

Based on the announced time of death, we estimate the death rate of the integrated emergency response system where both the airport and medical department take responsive actions at $5 \mathrm{~min}$ and $92 \mathrm{~min}$ from the time of occurrence. At $92 \mathrm{~min}$, the death rate is zero, because of the medical department response, which is consistent with our assumption. In the process of emergency response, the times of death for three fatalities are announced at 11:44, 11:49, and 12:06, which are 16 minutes, 21 minutes, and 38 minutes from the time of occurrence at 11:28. As presented in Figure 5, the dashed line is the mean death rate and the solid line is the simulated death rate. The simulated death rate appears valid in our empirical context, because the death rate changes during the disaster. Moreover, the slow increasing velocity and fast decrease make that the disaster can be controlled quickly. Therefore, our results based on this estimated death rate underestimate the true gains from improved responsiveness.

Throughout this empirical case, we compute the beneficial gains for both improved responsiveness and increased service capacity by using the expressions derived in Sections

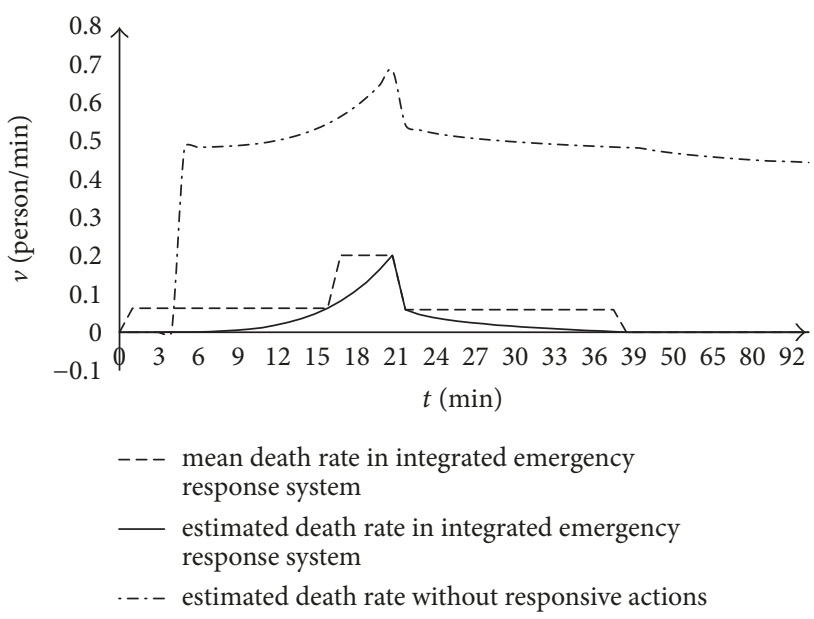

FIGURE 5: Estimated death rate curve of the integrated emergency response system.

4 and 5. First, we present the estimated death rate functions under responsive action and no responsive action as follows:

$$
\begin{gathered}
v^{r}(t)= \begin{cases}4.13 \times 10^{-7} t^{4.3} & 0 \leq t \leq 21, \\
-0.1412(t-21)^{0.12}+0.2 & 21 \leq t \leq 39,\end{cases} \\
v^{n r}(t)= \begin{cases}4.13 \times 10^{-7} t^{4.3} & 0 \leq t \leq 5, \\
4.13 \times 10^{-7} t^{4.3}+0.35 & 5 \leq t \leq 21, \\
-0.1412(t-21)^{0.12}+0.55 & 21 \leq t \leq T,\end{cases}
\end{gathered}
$$

where $T$ is the death ending time without responsive action and $\int_{0}^{92} v^{n r}(t) d t=42$, which is less than the number of serious casualties (52), indicating that the estimated death rate functions appear to be applicable.

6.2. Benefit of the Integrated Emergency Response System. The benefit of the integrated emergency response system is calculated as the difference in the number of relieved casualties with and without an airport's fast-preliminary response. Since this empirical case lacks data on medical department response time in the medical department emergency response system where only the medical department takes responsive action, we evaluate it based on actual data on the velocity of ambulances and the distance between medical departments and the airport. Based on accident reports from the 1960s to the 1980s, the fast-preliminary response was weakly prepared for and underequipped, where the medical department response time in the medical department emergency response system ranges from $25 \mathrm{~min}$ to $90 \mathrm{~min}$. The benefits of the integrated emergency response system compared to the medical department emergency response system are computed and displayed in Table 2.

In Table 2, the estimated benefits increase when the responsiveness of the medical department's medical department emergency response system decreases. Separated by time at $38 \mathrm{~min}$, the increments of benefits increase drastically 
TABLE 2: Benefits of an integrated emergency system for different medical department emergency responses.

\begin{tabular}{|c|c|c|c|c|c|c|c|c|c|c|c|}
\hline 25 & 28 & 30 & 32 & 35 & 38 & 40 & 50 & 60 & 70 & 80 & 90 \\
\hline 6.82 & 7.95 & 8.68 & 9.41 & 10.49 & 11.55 & 12.51 & 17.24 & 21.89 & 26.47 & 30.99 & 35.46 \\
\hline
\end{tabular}
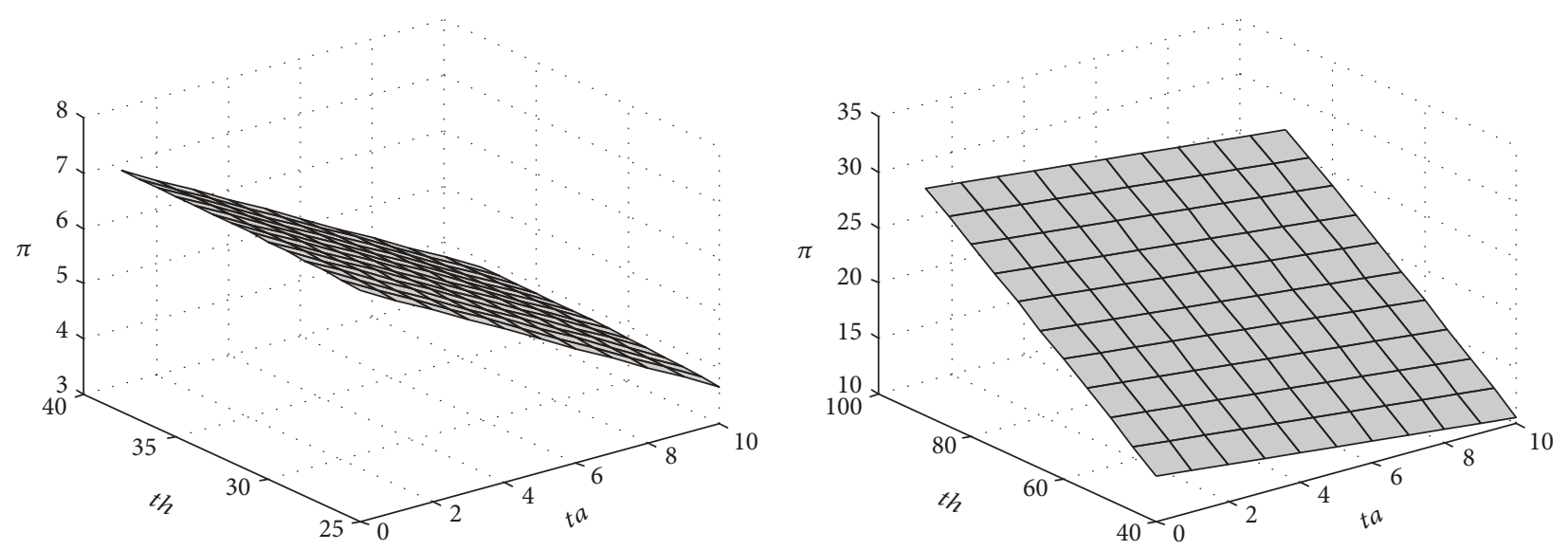

FIGURE 6: Benefits of an integrated emergency system as a function of $t_{a}$ and $t_{h}$.

but decrease both before and after the $38 \mathrm{~min}$. This indicates that a fast-preliminary strategy would be more beneficial when the medical department has a low responsive ability. In this instance, improved performance increases from 6 to 36 casualties when the responsiveness of the medical department emergency response system is low.

6.3. Welfare Gains from Increased Service Capacity. The welfare gains from increased service capacity can be estimated using the newly developed methodology. As mentioned in the accident report on United Airlines Flight 232, 7 firefights worked 30 minutes to extricate all casualties, and 34 ambulances worked 60 minutes to rapidly assess all casualties. Therefore, the service times of one person in the United Airlines Flight $232 \mathrm{crash}$ are $7.6 \mathrm{~min} /$ people $(30 / 296 \times 7+$ $60 / 296 \times 34)$, totaling 296 casualties and 111 deaths $(111 \times 0.1=$ 11.1). In comparison, the service times of one person in the Asiana Airlines Flight $214 \mathrm{crash}$ are $2.87 \mathrm{~min} /$ people, with a total of 307 casualties and 3 deaths. In addition, the elasticity of service time is estimated based on $r(\tau, s)=H \tau^{\gamma} s^{\varepsilon}$, and the estimated service time elastic is $\gamma=-0.066$. Using the above information, the evaluated welfare gains from the increased service capacity of a fast-preliminary response are approximately 1385 units of emergency supplies, noted that the outcomes are conservative with a relatively small discount factor.

6.4. Sensitivity Analysis. Finally, the sensitivity of parameters is analyzed to obtain insights into an efficient emergency response system design. Using the base numbers estimated for the Asiana Airlines Flight 214 crash, we vary the values for the key factors of the design of an emergency response system: the response time of airport $t_{a}$, service rate of the airport $u$, and medical department response time in an integrated emergency response system $t_{d}$. We also examine factors pertaining to the latest response time $t_{a}{ }^{M}$. We selected the ranges for these parameters based on representative values for accident response in a range of civil aviation disasters. That is, $t_{a} \in[0,10]$, corresponding to a waiting time between 0 and 10 minutes; $u \in[0,2]$, corresponding to rapid assessment accounting for at least 0.5 minutes; and $t_{d} \in[25,360]$, corresponding to the estimated data on types of disasters.

Figure 6 shows the value of performance increments of the integrated emergency response system as a function of airport response time $t_{a}$, as well as medical department response time in the only medical department emergency response system $t_{h}$. The marginal value of increased responsiveness becomes important for lower values of airport response time and higher values of only medical department response time. In some cases, substantial benefits are gained from considering a less responsive medical department emergency response system. Conversely, when the medical department emergency system has higher responsiveness, a costefficient integrated emergency response system is favored, and even the value of time is high. Therefore, the emergency manager must be aware of the balance of adopting either responsive or cost-efficient emergency response systems.

Figure 7 shows that, for the medical department emergency response system, where waiting time for casualties is considerable, both the impact of an airport's service capacity and medical department response time in the integrated emergency system significantly benefit the integrated emergency response system. In addition, the airport's service rate has a positive linear impact on the benefit from increased responsiveness made available through an airport's fastpreliminary strategy in the integrated emergency response system. However, the medical department response time in the integrated emergency system has a negative effect. The second diagram in Figure 7 illustrates that the negative impact of medical department response time in the integrated emergency system is obscure and reduces to zero when it is 

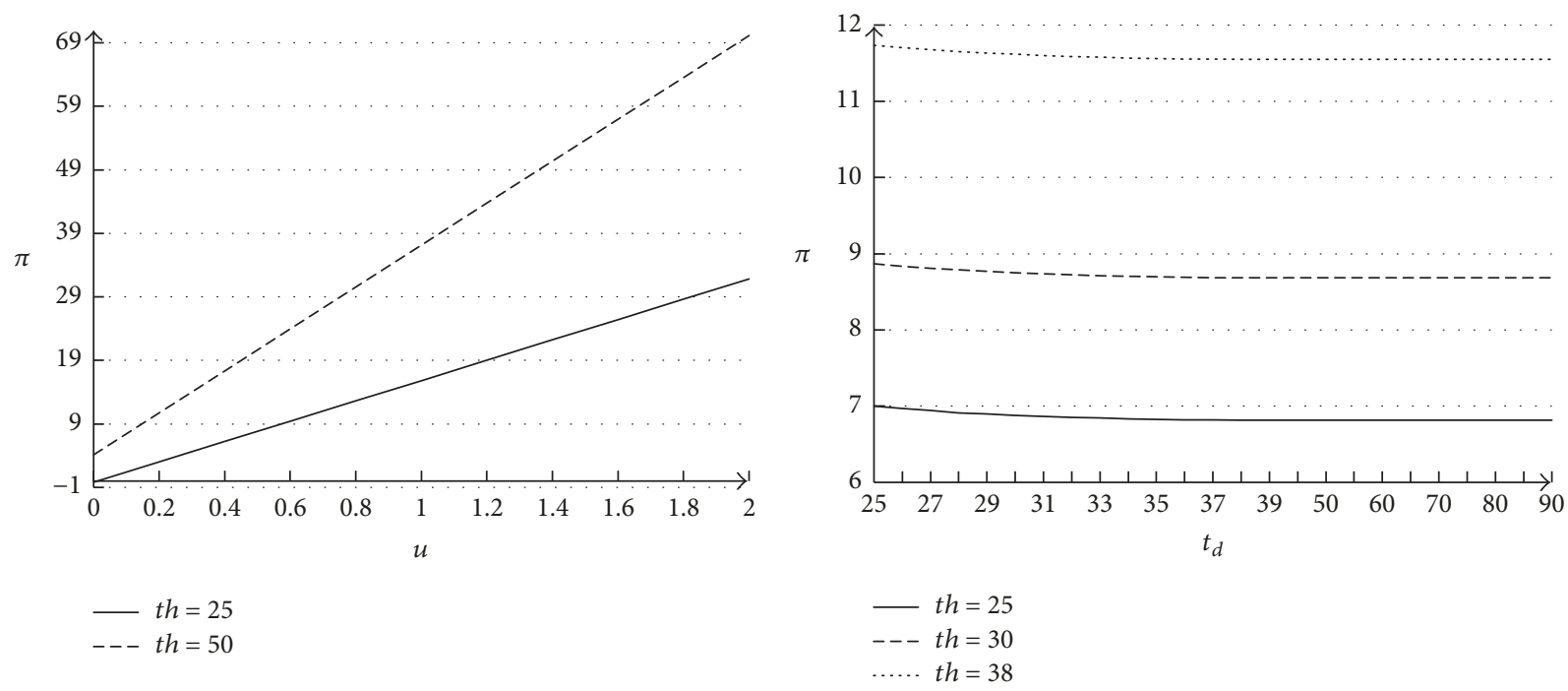

FIGURE 7: Benefits of an integrated emergency system as a function of $u$ or $t_{d}$.
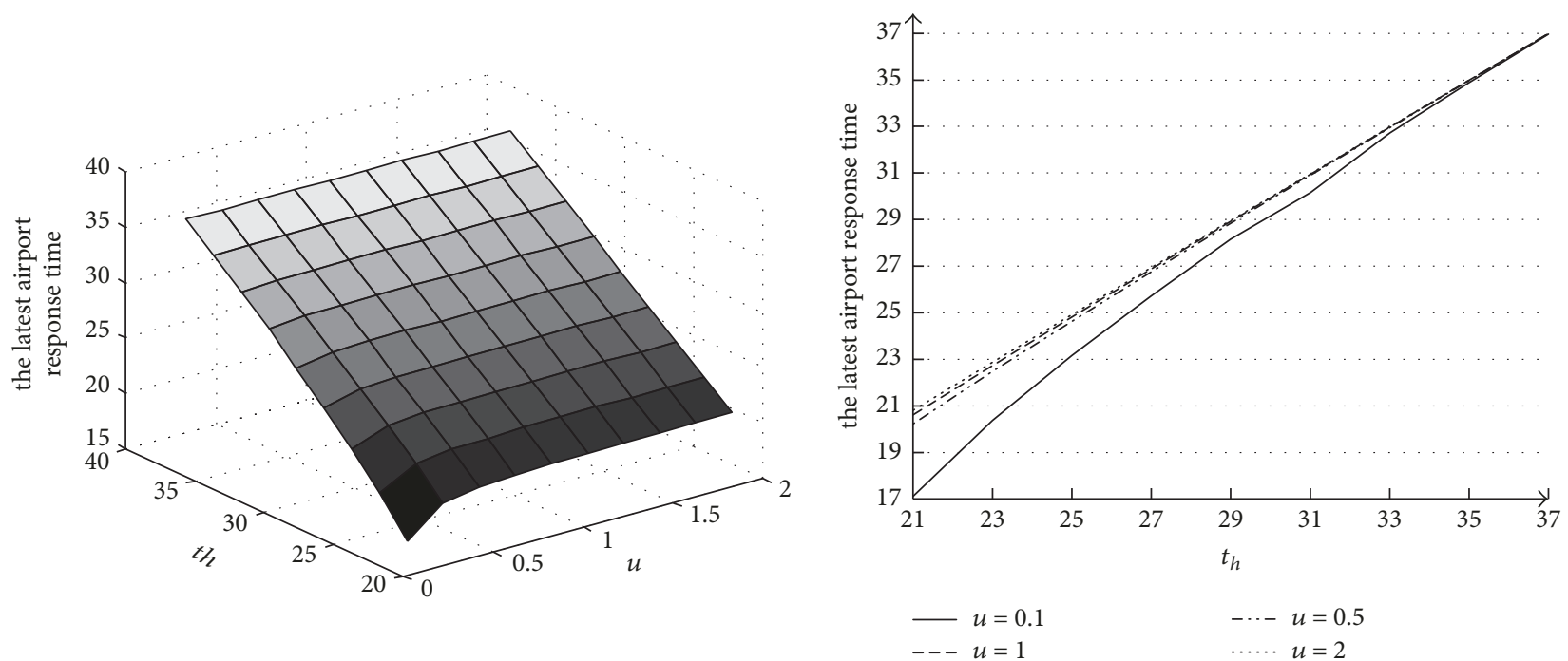

FIGURE 8: Effect of service rate on the latest airport response time.

later than $38 \mathrm{~min}$ in this empirical example. This is because the response time value decreases with the decreasing death rate with time after the critical point.

Finally, Figure 8 shows the latest response time of an airport in the integrated emergency response system as a function of the service rate (related to service capacity). The latest airport response time is more sensitive to $u$, because a less severe crash afforded casualties an increased waiting time for relief in the Asiana Airlines Flight 214 crash. Furthermore, Figures 6-8 clarify that if the strategies of improved responsiveness and service rate become more lenient-both responsiveness and service capacity increase - the integrated emergency response system may be imperative to the main value in small-scale disasters. In other words, strategies for today's airport responses should be reengineered in the future. For example, the primary concern for a large-scale accident may be to increase responsiveness, while for a small-scale accident, it may be to increase service capacity, which requires more waiting time to fully prepare.

\section{Conclusions}

Considering the two potential effects of improved responsiveness made available through a fast-preliminary strategy in the integrated emergency response system and increased service capacity with the development of soft and hard investment in emergency response, our study described the response time value curve during a civil aviation disaster. Furthermore, the study evaluated the benefits derived from improved responsiveness viewed the medical department response system as a benchmark. Finally, it developed a new methodology to measure the welfare gains from increased service capacity with reference to existing welfare estimation techniques of compensating variation. By highlighting the 
interaction between airports' fast-preliminary response and medical departments' subsequent response and by addressing the latest response time of an airport, this study makes several important theoretical and practical contributions to the field of management, especially emergency management.

This research extended the application of emergency response strategies. On the one hand, our study represents a first effort to quantify gains to understand and evaluate the value proposition of improved emergency response systems. On the other, our research applies and extends these methodologies to quantify the important welfare impact of increased service capacity on the development of soft and hard investment in emergency response. Two empirical examples were applied in our study. We determined that the benefit of an integrated emergency response system is between 5 and 36 casualties in these two cases, and the welfare gains based on increased investment in emergency response are conservatively 1385 units of emergency supplies. Here, the welfare of 13845 emergency supplies indicates that the ending time of emergency response will be in advance with $(23 \div$ number of emergency supplies) hours; for example, the increased service capacity can help the 1989 accident response terminate ahead of 0.56 hours. However, the saved people because of the enhanced service capacity are not computed in our paper, which can be worked out with the response time value function.

Furthermore, with high levels of probability for accidents and traveling populations, airports face significant emergency management challenges. To deal with these, airport managers must reduce the potential impact of an accident on their operations and develop appropriate financial safety nets. From an international perspective, many airports have committed to achieving ambitious emergency goals. However, most struggle to bridge the gap between their aspiration and the practical steps needed to achieve their objectives. The evaluation of the value proposition of emergency response systems in this study provides an important view by which to address this problem.

Our theoretical study has generated numerous practical implications that warrant further analysis. First, based on our study, airport decision-makers need to more clearly define their response time and implement procedures to improve service capacity during an emergency response. Service capacity can be achieved by improving technological capabilities or training soft skills, while, in terms of how it functions or being even better, all operations should move away from a single sector to a cross-sectorial approach. This specialization will improve service capacity. Moreover, the decision to select or not select a fast-preliminary strategy should consider the severity of the disaster and medical department responsiveness without an airport's first response.

Our work provides several avenues for future research. A natural extension of our study is to consider the network designs and supply chain management aspects existing between airports and suppliers [35]. This examination will provide an opportunity to develop models that evaluate the coordination mechanisms and relationships between airports, governments, the public, and businesses [36]. In addition, there is an opportunity to study the multistage stochastic or dynamic programming aspects related to emergency management. By further step, operational costs should be introduced into benefit or welfare gains, and the methodologies should be examined and modified by using a rich data set.

\section{Conflicts of Interest}

The authors declare that they have no conflicts of interest.

\section{Acknowledgments}

This study is supported by the National Nature Science Foundation of China (NSFC) (Grant nos. 71572096, 71373188, and U1333115).

\section{References}

[1] H.-J. Shyur, "A quantitative model for aviation safety risk assessment," Computers \& Industrial Engineering, vol. 54, no. 1, pp. 34-44, 2008.

[2] D. S. Kim and W. C. Yoon, "An accident causation model for the railway industry: Application of the model to 80 rail accident investigation reports from the UK," Safety Science, vol. 60, pp. $57-68,2013$.

[3] B. K. Ning, "Spatial-temporal distribution of seismic disasters and emergency response," Working Paper, Institute of Geology, China Earthquake Administration, 2010.

[4] M. S. Habib, Y. H. Lee, and M. S. Memon, "Mathematical Models in Humanitarian Supply Chain Management: A Systematic Literature Review," Mathematical Problems in Engineering, vol. 2016, Article ID 3212095, 2016.

[5] J. R. Hicks, "Consumers' surplus and index-numbers," Review of Economic Studies, vol. 9, no. 2, pp. 126-137, 1942.

[6] G. Haddow, J. Bullock, and D. P. Coppola, Introduction to Emergency Management, Butterworth-Heinemann, 2017.

[7] W. Ni, J. Shu, and M. Song, "Location and Emergency Inventory Pre-Positioning for Disaster Response Operations: MinMax Robust Model and a Case Study of Yushu Earthquake," Production and Operations Management, vol. 27, no. 1, pp. 160183, 2018.

[8] R. Das and S. Hanaoka, "Relief inventory modelling with stochastic lead-time and demand," European Journal of Operational Research, vol. 235, no. 3, pp. 616-623, 2014.

[9] Q. C. Meng, Y. Guo, P. X. Zhao et al., "Optimization and simulation for airport emergency inventory with replacement," International Journal of Simulation Modelling, vol. 16, no. 1, pp. 133-144, 2017.

[10] A. M. Anaya-Arenas, J. Renaud, and A. Ruiz, "Relief distribution networks: a systematic review," Annals of Operations Research, vol. 223, pp. 53-79, 2014.

[11] H. O. Mete and Z. B. Zabinsky, "Stochastic optimization of medical supply location and distribution in disaster management," International Journal of Production Economics, vol. 126, no. 1, pp. 76-84, 2010.

[12] Z.-H. Hu and J.-B. Sheu, "Post-disaster debris reverse logistics management under psychological cost minimization," Transportation Research Part B: Methodological, vol. 55, pp. 118-141, 2013.

[13] C. Liu, Q. Zeng, H. Duan, M. Zhou, F. Lu, and J. Cheng, "ENet modeling and analysis of emergency response processes 
constrained by resources and uncertain durations," IEEE Transactions on Systems, Man, and Cybernetics: Systems, vol. 45, no. 1, pp. 84-96, 2015.

[14] C. G. Rawls and M. A. Turnquist, "Pre-positioning planning for emergency response with service quality constraints," $O R$ Spectrum, vol. 33, no. 3, pp. 481-498, 2011.

[15] V. D. R. Guide Jr., G. C. Souza, L. N. van Wassenhove, and J. D. Blackburn, "Time value of commercial product returns," Management Science, vol. 52, no. 8, pp. 1200-1214, 2006.

[16] Z. Carmon, J. G. Shanthikumar, and T. F. Carmon, "A psychological perspective on service segmentation models: the significance of accounting for consumers' perceptions of waiting and service," Management Science, vol. 41, no. 11, pp. 1806-1815, 1995.

[17] P. T. Pons, J. S. Haukoos, W. Bludworth, T. Cribley, K. A. Pons, and V. J. Markovchick, "Paramedic response time: Does it affect patient survival?” Academic Emergency Medicine, vol. 12, no. 7, pp. 594-600, 2005.

[18] B. Berg, A. Gafni, and F. Portrait, "Attributing a monetary value to patients' time: A contingent valuation approach," Social Science \& Medicine, vol. 179, pp. 182-190, 2017.

[19] A. Chen, N. Chen, and J. Li, "During-incident process assessment in emergency management: Concept and strategy," Safety science, vol. 50, no. 1, pp. 90-102, 2012.

[20] D. Richardson, "Increase in patient mortality at 10 days associated with emergency department overcrowding," Medical Journal of Australia, vol. 184, pp. 213-216, 2006.

[21] L. V. Green and P. J. Kolesar, "Improving emergency responsiveness with management science," Management Science, vol. 50, no. 8, pp. 1001-1014, 2004

[22] S. Saghafian, W. J. Hopp, M. P. Van Oyen, J. S. Desmond, and S. L. Kronick, "Patient streaming as a mechanism for improving responsiveness in emergency departments," Operations Research, vol. 60, no. 5, pp. 1080-1097, 2012.

[23] H. Song, A. L. Tucker, and K. L. Murrell, "The diseconomies of queue pooling: An empirical investigation of emergency department length of stay," Management Science, vol. 61, no. 12, pp. 3032-3053, 2015.

[24] N. Kunz, G. Reiner, and S. Gold, "Investing in disaster management capabilities versus pre-positioning inventory: A new approach to disaster preparedness," International Journal of Production Economics, vol. 157, no. 1, pp. 261-272, 2014.

[25] Z. Akşin, B. Ata, S. M. Emadi, and C.-L. Su, "Structural estimation of callers' delay sensitivity in call centers," Management Science, vol. 59, no. 12, pp. 2727-2746, 2013.

[26] D. Nohrstedt, "Does Adaptive Capacity Influence Service Delivery? Evidence from Swedish Emergency Management Collaborations," Public Management Review, vol. 17, no. 5, pp. 718-735, 2015.

[27] P. Yi, S. K. George, J. A. Paul, and L. Lin, "Hospital capacity planning for disaster emergency management," Socio-Economic Planning Sciences, vol. 44, no. 3, pp. 151-160, 2010.

[28] R. Luscombe and E. Kozan, "Dynamic resource allocation to improve emergency department efficiency in real time," European Journal of Operational Research, vol. 255, no. 2, pp. 593603, 2016

[29] D. C. Novak and J. L. Sullivan, "A link-focused methodology for evaluating accessibility to emergency services," Decision Support Systems, vol. 57, no. 1, pp. 309-319, 2014.

[30] J. A. Hausman, "Exact consumer's surplus and deadweight loss," American Economic Review, vol. 71, no. 4, pp. 662-676, 1981.
[31] Q. M. Li, Y. L. Deng, C. Liu, Q. T. Zeng, and Y. Lu, "Modeling and analysis of subway fire emergency response: An empirical study," Safety Science, vol. 84, pp. 171-180, 2016.

[32] G. Mohammadi, "Road crash injuries and fatalities in Isfahan, Iran from March 2006 to March 2009," International Journal of Injury Control and Safety Promotion, vol. 21, no. 4, pp. 361-366, 2014.

[33] R. Chowdhury, B. N. Rao, and A. M. Prasad, "High dimensional model representation for piece-wise continuous function approximation," Communications in Numerical Methods in Engineering, vol. 24, no. 12, pp. 1587-1609, 2008.

[34] E. Brynjolfsson, Y. J. Hu, and M. D. Smith, "Consumer surplus in the digital economy: estimating the value of increased product variety at online booksellers," Management Science, vol. 49, no. 11, pp. 1580-1596, 2003.

[35] Q. S. Zhou and T. L. Olsen, "Inventory rotation of medical supplies for emergency response," European Journal of Operational Research, vol. 257, no. 3, pp. 810-821, 2017.

[36] J. Yang, H. Liu, X. Yu, and F. Xiao, "Emergency coordination model of fresh agricultural products' three-level supply chain with asymmetric information," Mathematical Problems in Engineering, vol. 6, Article ID 2780807, pp. 1-9, 2016. 


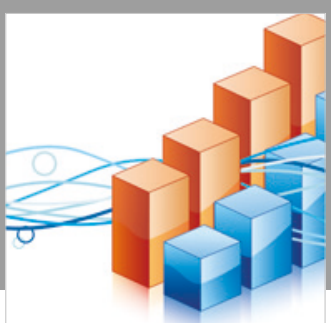

Advances in

Operations Research

\section{-n-m}
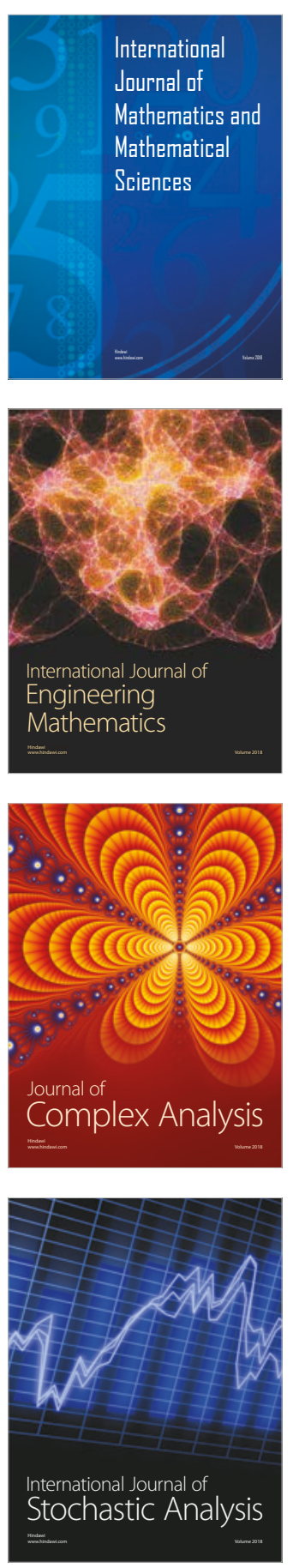
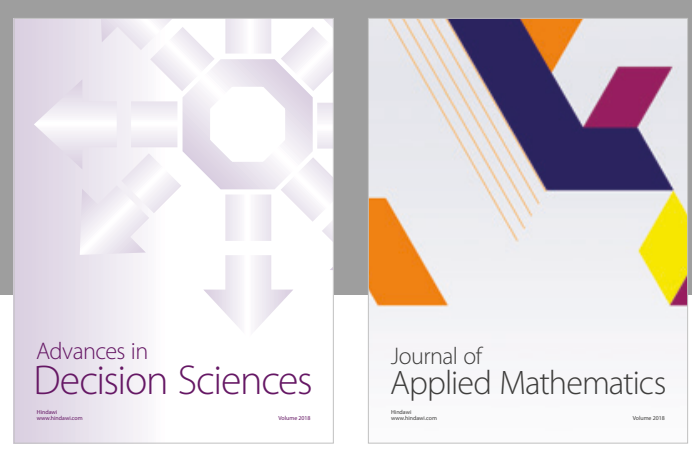

Journal of

Applied Mathematics
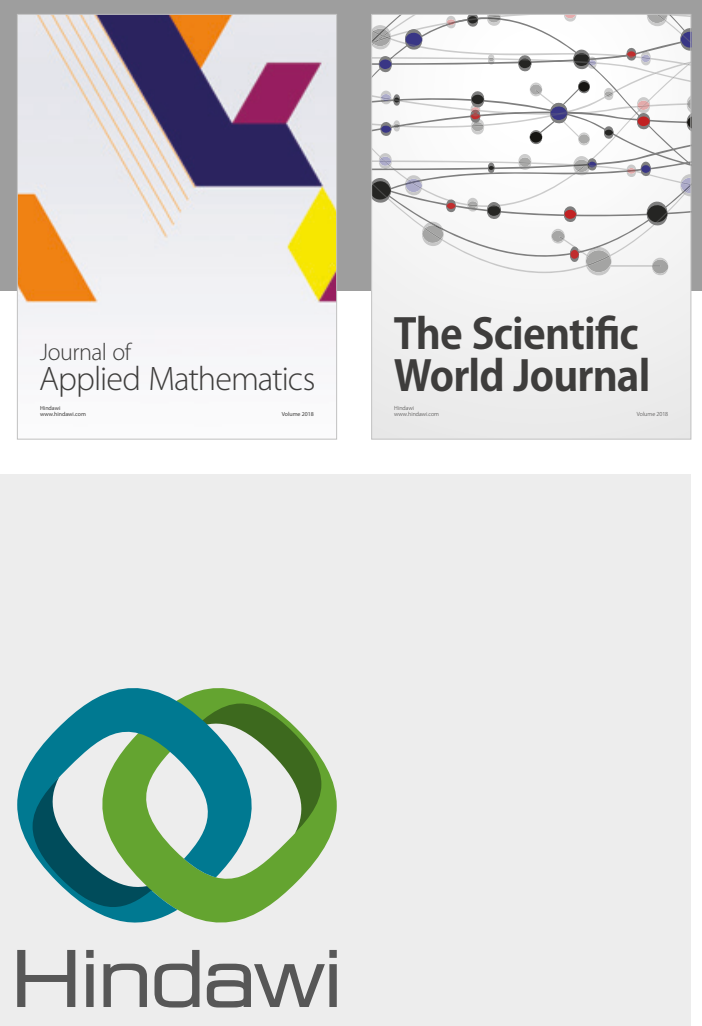

Submit your manuscripts at

www.hindawi.com

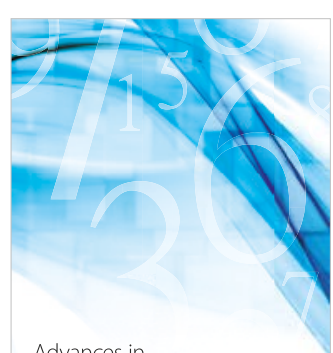

Advances in
Numerical Analysis
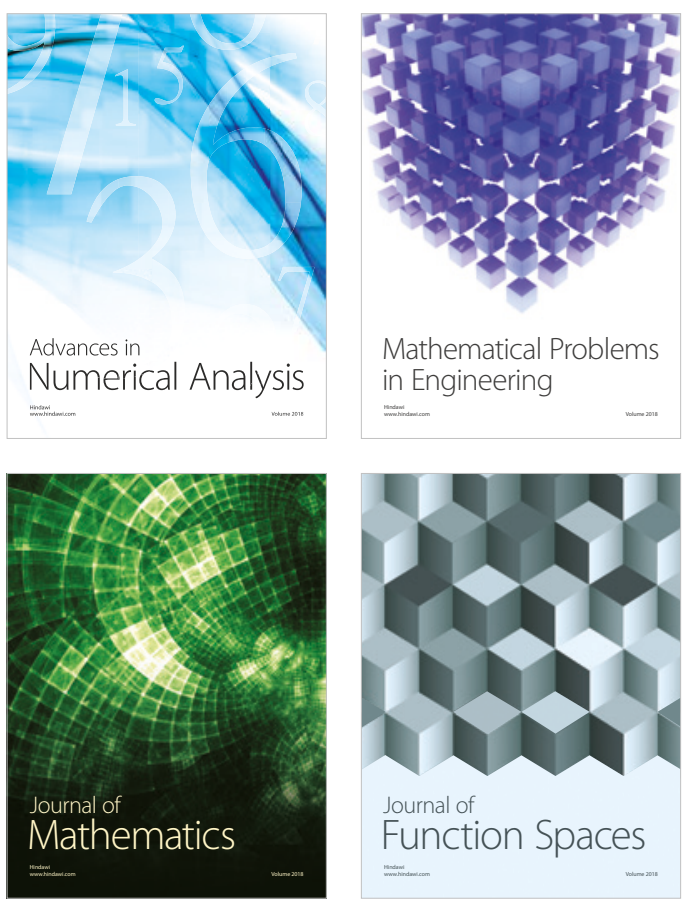

Mathematical Problems in Engineering

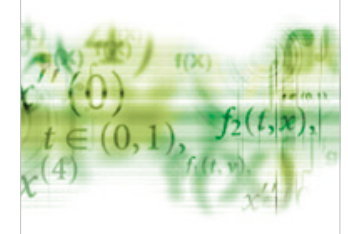

International Journal of

Differential Equations

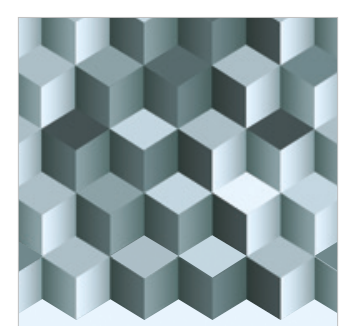

Journal of

Function Spaces

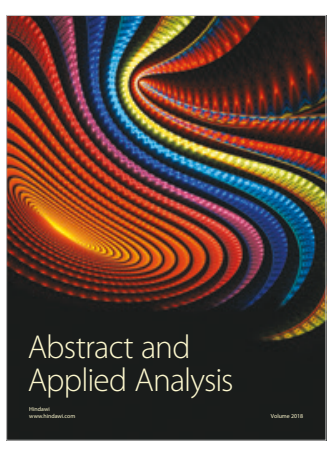

The Scientific

World Journal

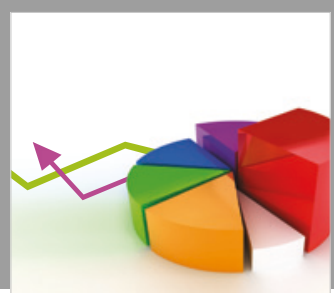

Journal of

Probability and Statistics
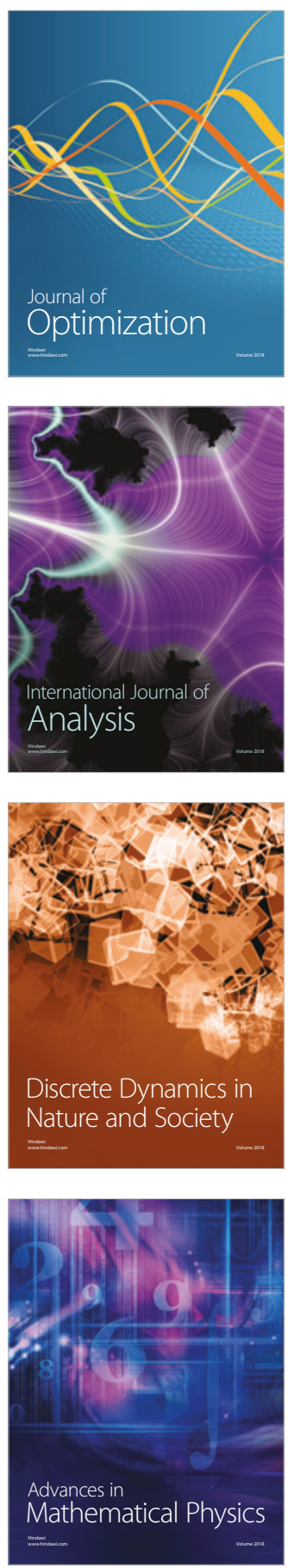